\title{
A Mismatch Made in Heaven: A Hedonic Analysis of Overeducation and Undereducation
}

\author{
by \\ Daniel P. McMillen \\ Department of Economics \\ University of Illinois at Chicago \\ and \\ Paul T. Seaman \\ Department of Economic Studies \\ University of Dundee \\ and \\ Larry D. Singell, Jr. \\ Department of Economics \\ University of Oregon
}

December 2003

Please direct correspondence to: Larry D. Singell, Jr.

Department of Economics

University of Oregon

Eugene, OR 97403-1285 


\begin{abstract}
Prior work suggests coordination failure between labour and education markets leads some workers to have educational qualifications in excess of those specified for the job (overeducation) and others to have less (undereducation). This paper empirically models and tests the hypothesis that overeducation and undereducation arise out of a hedonic matching process that maximises net benefits to workers and firms over the life of the match. Specifically, the overeducated begin in low-paying, entry-level jobs early in their careers that prepare them for higher-paying future positions that require their educational background, whereas the undereducated start in lower-paying, exactly-educated jobs that can signal skills necessary for promotion. The empirical model shows that, because all workers are exactlyeducated during at least a portion of their career, the type of educational match cannot be directly identified using a cross-section, but may be imputed from the differences between predicted and observed qualifications of the worker and predicted and observed requirements of the firm. The empirical analysis uses a rich cross-section of British working-age males to identify match types. Using contemporaneous, forward- and backward-looking data, we confirm that over and undereducated matches differ in their on-the-job training and promotion opportunities, which yield a trade-off in the pre- versus post-match return to human capital.
\end{abstract}

JEL Classification: J24, J31

Key Words: Over and Undereducation 


\section{Introduction}

Over the last two decades there has been much concern by researchers and policy makers over the apparent lack of coordination between the labour market and the educational system that leads some workers to have educational qualifications in excess of those specified for the job (overeducation) and others to have less (undereducation). Cross-sectional studies using U.S., European, and Asian data sources indicate that between 30 and 40 percent of workers have educational qualifications that either exceed or fall short of firm requirements at a particular point in time (e.g., Sicherman, 1991; Alba-Ramirez, 1993; Ng 2001). Moreover, a meta-analysis by Groot and Maassen van den Brink (2000b) shows no significant change in the extent of this apparent skill mismatch between workers and firms over the last 20 years. Thus, overeducation and undereducation appear to be pervasive and persistent phenomena in industrialised countries.

A large empirical literature treats both overeducation and undereducation as evidence of an imbalance in the supply of and demand for skills (Rumberger 1981 and 1987; Manacorda and Petrongolo, 2000). For example, short-run coordination failure between worker qualifications and firm requirements could occur if rapid technological advancement draws educated workers into jobs traditionally held by lower-skilled workers who cannot readily acquire more education (Borghans and de Grip, 2000). Mismatch in the skills market is supported by a number of empirical wage studies that include years of required education and measures of whether the worker has more or less education than required. These studies find that workers whose qualifications equal firm requirements earn a higher return to education than those who do not (Duncan and Hoffman, 1981; Hersch,1991; Vahey 2000).

Recently, two equilibrium rationales have been proposed for the presence of overeducation. First, several papers examine whether worker qualifications might exceed firm requirements due to the substitutability or complementarity between education and onthe-job training (Mendes de Oliveira et al, 2000). Workers might be identified as overeducated if, for example, education and on-the-job training are substitutes in production such that job entrants who possess more than the minimum educational requirements do not require further training. While not explicitly studied in prior work, substitutability between education and on the job training could also lead to undereducation if workers can use on-thejob training as a substitute for formal education. On the other hand, complementarity between education and training could imply human capital differences increase throughout a career because well-educated workers benefit more from training. An empirical paper by van 
Smoorenburg and van der Velden (2000) finds that substitutability and complementarity between initial education and on-the-job training are both possible and depend on factors such as the match between the job and field of study and the "narrowness" of educational training.

Secondly, severalpapers model overeducation as a result of career mobility. For example, Sicherman and Galor (1990) develop a theoretical model in which workers start in jobs for which they are overeducated in exchange for a higher probability of moving up the job hierarchy. They test this hypothesis using data for working-age males from the 1976-81 waves of the PSID and find that the correlation between the effect of education on wages and its effect on the probability of moving to a "better" job is negative and significant. This result suggests that overeducated workers trade off a lower return to education for an increased probability of promotion. Nonetheless, equilibrium rationales have not been put forward for the presence of undereducated workers.

In this paper, career mobility and possible tradeoffs between education and on-the -job training arise in a hedonic matching model where worker skills can meet, exceed, or fall short of stated job requirements in equilibrium. Specifically, a discrete hedonic matching model shows that worker and firm heterogeneity elicit different match types, and only some workerfirm pairings yield a match where it is jointly optimal for worker qualifications to equal firm requirements over all periods of the match (i.e., an exactly-educatedtype match). The optimal matching process can also yield overeducated and undereducated-type matches in which worker qualifications match firm requirements only for a portion of the time the worker and firm are matched, which could give rise to overeducation or undereducation in a crosssection. The model predicts that overeducated-type matches begin with workers in lowerpaying, entry-level jobs early in their career that train them for higher-paying future positions that require their educational background, whereas undereducated type matches start with workers in lower-paying jobs for which they are exactly educated and that provide them the opportunity to acquire training and signal that they have the necessary skills for promotion into a higher-paying job.

A crucial outcome of the model is that all workers are predicted to have worker qualifications that meet firm requirements at some point during the match. This implies that prior work, which has relied on the observed educational match in a cross-section or a short panel, may have misidentified the match type of some workers whose qualifications meet firm requirements, because these workers could be in an overeducated or undereducatedtype of match as we have defined it. Our discrete hedonic matching model builds on prior 
work by providing a method to impute the match type from the difference between predicted and observed qualifications of the worker and the predicted and observed requirements of the firm that can be derived from a jointly-estimated ordered probit model of worker qualifications and firm requirements. We estimate a joint-ordered probit model using uniquely-detailed data for British working-age males contained in the Social Change and Economic Life Initiative survey (SCELI), which is used to predicted the worker match type (i.e., overeducated, undereducated, and exactly educated). The predicted match types correctly identify the majority of workers who are observed to be overeducated and undereducated, and indicate that a significant portion of workers who are observed to be exactly-educated are not in an exactly-educated type match.

The predicted match types are used in a second set of empirical analyses that takes advantage of the forward-looking and backward-looking data contained in SCELI to examine whether past or future opportunities for on-the-job training and promotions differ as expected across the match types. In addition, several wage equations examine whether those workers in overeducated and undereducated-match types have steeper wage profiles than those in exactly-educated match types, reflecting the expected trade off between a lower pre-match return to human capital and a higher post-match acquisition of human capital and subsequent promotion return. The results provide some of the first formal evidence that overeducation and undereducation can occur in labour market equilibrium and that an empirical assessment of worker-firm matches needs to take account of the fact that a match occurs over multiple periods.

\section{Empirical Model}

\section{A. Two Illustrations of Career Mobility}

By definition, overeducation or undereducation occur when the observed educational qualifications of the worker $(Q)$ do not match the stated educational requirements for the job $(R)$ at a given time. However, a worker-firm match often occurs over multiple periods and, thus, may reflect the objectives of the worker and the firm over the life of the match and not just for a single period. We develop a simple empirical hedonic matching model that shows an overeducated-type (undereducated-type) match yields $Q>R(Q<R)$ for some portion of the time the worker and the firm are matched and results from the fact that these workers move up the job-skill hierarchy with experience. To lay a foundation for the empirical model it is useful to begin with two simple illustrations where career mobility can yield an overeducated- or an undereducated-type of match. 
There are a number of practical examples of an overeducated-type match. For example, most U.K. police officers enter the force with secondary school qualifications, which qualify them to be a patrol officer. However, some people enter the police force with a university degree. These workers generally begin their career as a patrol officer because this experience improves their subsequent performance when they are promoted into jobs that require their qualifications, such as a detective. Thus, university-educated patrol officers accept jobs for which they are overeducated in exchange for training and an expected future promotion into a job for which they are exactly educated.

Alternatively, whereas most detectives have a university degree, some patrol officers with only secondary school qualifications are promoted to detective because their on-the-job experience in the field reveals that they have the necessary skills and personal attributes to be a successful detective. These secondary school-educated detectives begin in a patrol officer job for which they are exactly educated but are promoted into jobs for which they may be viewed as undereducated because their qualifications are below those of many detectives who have a university degree. It follows that the experience of these secondary school-educated detectives substitute for the skills and/or the signal of ability provided by a university degree and permit them to move up the job hierarchy.

Though both the secondary school-educated and the university-educated officers may be promoted from the status of patrol officer to that of detective, the career paths are likely to differ in terms of the speed with which promotions are secured. Whereas the universityeducated officers may have already been identified as candidates for detective positions and are more likely to receive both training and promotions as an inducement to stay in the police force rather than enter other occupations, secondary school-educated officers are hired with no observed skills to differentiate them from others in their police academy cohort. Consequently, they must rely on the development of their on-the -job skills and demonstrated ability to signal promotion readiness. Thus, whereas both categories of officers may in time reach the desired objective of detective status, university-educated officers are likely to be promoted with less experience than secondary school-educated officers. Moreover, those who are likely to do well as a university-educated (secondary school-educated) detective are more likely to self-select into this profession and accept the trade-off of some initial "mismatch" (further training and demonstration of ability) to receive the wage increase associated with promotion.

These simple illustrations highlight two important points. First, they suggest that standard wage equations may confound the pre- versus post-match return to human capital, 
because the pre-match level of human capital can affect subsequent opportunities for on-thejob training and promotion. In fact, these illustrations suggest that the wage profile may be steeper for workers in an ove reducated- or undereducated-type of match. Specifically, a university-educated patrol officer accepts a lower-skilled position in order to obtain the requisite training and subsequent promotion to detective. Thus, whereas this overeducated worker would likely initially earn more if he or she matched in a job that required a university degree, the worker trades off an initially low return to education for a subsequent promotion return (e.g., Sicherman and Galor, 1990). Likewise, a secondary schooleducated patrol officer who is promoted to detective is likely to experience faster salary growth than one who is not promoted to detective. In both cases, the greater wage growth likely reflects heterogeneity across firms in the opportunity for promotion and heterogeneity across workers in their willingness to acquire on-the -job training and their ability to take advantage of such promotion opportunities throughout their career. ${ }^{1}$

Second, these illustrations suggest that workers who are observed to have $Q>R$ or $Q<R$ at a particular point in time do not constitute the full set of workers who are in an overeducated- or undereducated-type of match. In particular, the illustrations show that the pool of exactly-educated workers may include, in addition to workers who are exactlyeducated throughout their career, previously overeducated workers who have been promoted into exactly-educated jobs or undereducated-type workers who are (at present) exactly educated because they have yet to move up the job ladder. Prior work has not distinguished between these groups of exactly-educated workers, but instead has compared workers who are observed to be overeducated or undereducated with those who are observed to be exactlyeducated at a particular point in time. This identification problem is further compounded by the fact that traditional data sources do not permit a direct test of the possible differences in labour market outcomes among match types, since the expected transition to or from an exactly-educated job by overeducated- and undereducated-type workers is not necessarily observed in a cross-section or a short panel.

Our empirical model suggests a possible means of indirectly distinguishing the overeducated, undereducated, and exactly-educated type of match within a cross-section by comparing the discrete, observed educational qualifications of the worker $(Q)$ and the

\footnotetext{
${ }^{1}$ It is important to note, however, that overeducat ed- and undereducated-type jobs that offer a potential promotion return would be more desirable than those for which the worker is exactly-educated throughout a career, all else being equal. Thus, from a market perspective, these jobs would have to pay less early on in a career to ensure that jobs that require "similarly-educated" workers have the same life-cycle earnings. These market pressures would tend to reinforce the steeper wage profile for workers who are in overeducated- and undereducated-type matches versus those who are exactly educated throughout a career.
} 
discrete, educational requirements of the firm $(R)$ with their predicted, continuous values $\left(Q^{*}\right.$ and $R^{*}$ ) that exploit the information in the observed match between workers and firms. In particular, the empirical model shows how the match type can be identified by firm heterogeneity in the match between $R$ and $R^{*}$, controlling for the observed qualifications of the worker, and worker heterogeneity in the match between $Q$ and $Q^{*}$, controlling for the observed requirements of the firm. ${ }^{2}$

\section{B. The Worker Qualification and Firm Requirement Choice}

The analysis first considers workers' utility-maximizing qualification choice and firms' profit-maximizing requirement choice in isolation before considering the joint matching process. It is important to note that, whereas the match occurs over time, we assume for simplicity that the educational choice of the worker and the requirement choice of the firm are made once and do not change over the course of the match. Moreover, although the joint matching process between workers and firms is likely to imply a strong correlation between $Q$ and $R$, we assume the qualification choice of the worker and the requirement choice of an individual firm are made prior to the match and are independent. Nonetheless, the expected correlation between $Q$ and $R$ is explicitly part of the hedonic matching model.

For the qualification decision, human capital theory assumes that individuals choose their education level in order to maximize utility, which depends on the rate of return to education. To formalize this process, we adopt a random utility approach where an individual $i$ obtains a level of education, $Q_{i}^{*}$, if the utility from this choice exceeds that of its alternatives. The actual level of education for individual $i, Q_{i}^{*}$, is unobserved and is modelled as a linear index function:

$$
Q_{i}^{*}=\alpha X_{i}+\varepsilon_{i}
$$

where $a^{\prime}$ is a vector of parameters associated with personal, family-background, and labour market measures, $X_{i}$, that determine the rate of return to education, and $e_{i}$ is a normally distributed error term that measures individual-specific random variation in the education level. In other words, (1) indicates that workers choose $Q_{i}^{*}$ based on the rate of return to education, which depends on factors such as personal ability and attitudes towards work,

\footnotetext{
${ }^{2}$ Bauer (2002) uses a large German panel data set to show that the difference in the returns to over- and undereducation disappears after controlling for differences in unobserved heterogeneity, which suggests that wages may reflect characteristics of the match that are known to workers and firms but not generally observed by the econometrician. Likewise, Robst (1995) shows that the likelihood of being overeducated declines with a measure of college quality, which again suggests wage heterogeneity in the match.
} 
family access to financial and human capital, and differences in the job mix and job market information of local labour markets.

The optimal education level in (1) is continuous, but a qualification is obtained when a worker's education level meets or surpasses a discrete, externally-verifiable threshold. For example, in England an individual must attend school from age 5 until age 16, at which point they can sit GCSE exams. However, a student who continues on to age 18 can take exams that, if passed, yield a superior secondary school qualification (i.e. 'A' levels). At the same time, students who have one year of university have not crossed the threshold for a university degree and thus their secondary school qualifications are their highest qualification.

In our data the observed qualification levels are comprised of three ordered values, the government minimum education level $\left(Q_{i}=0\right)$, at least one A-level or equivalent $\left(Q_{i}=1\right)$, and a university degree $\left(Q_{i}=2\right)$. Thus, following our subsequent empirical analysis, equation (1) can then be expressed as:

$$
\begin{aligned}
& Q_{i}=0 \quad \text { if } \quad \alpha^{\prime} X_{i}+\varepsilon_{i} \leq 0 \\
& Q_{i}=1 \quad \text { if } \quad \mu_{A} \geq \alpha^{\prime} X_{i}+\varepsilon_{i}>0 \\
& Q_{i}=2 \quad \text { if } \quad \alpha^{\prime} X_{i}+\varepsilon_{i}>\mu_{A}
\end{aligned}
$$

Equations (2.1) through (2.3) form the basis of an ordered-probit model of qualification choice for individual i. $Q_{i}$ is the qualification level that results from the latent, utilitymaximizing education level.

Likewise, following producer theory, we assume that a firm hires workers with a given education level in order to maximize profits. Like the individual model, the profitmaximizing education level for a worker in a given job $\left(R_{k}^{*}\right)$ is unobserved and is expressed as a linear index function:

$$
R_{k}^{*}=\beta^{\prime} Z_{k}+u_{k}
$$

where $\beta$ ' is a vector of coefficients for a set of firm, job, and labour market characteristics, $Z_{k}$, that affect the return to a given education level, and $u_{k}$ is a normally-distributed error term that measures firm-specific random variation in the return. In other words, (3) indicates that qualifications, $R_{k}^{*}$, based on their benefits to the firm, which depends on factors such as how firm and job attributes affect the net return to education and how labour-market conditions affect the cost of changing educational requirements.

Although the education level is continuous, a qualification requirement is the smallest discrete qualification that is sufficient to properly perform the job. For example, a firm may 
require a university degree because a secondary school qualification does not provide the necessary skills to perform the job properly. On the other hand, while a university degree may be sufficient, one year of university may be what is necessary to properly perform the job. Thus, the stated educational qualification may exceed what is necessary to properly perform the job, particularly if on-the-job training can substitute for formal education.

These data, like that for individual qualifications, includes three possible requirement levels. Thus, the firm's qualification choice can be represented as an ordered-probit model using (3):

$$
\begin{array}{lll}
R_{k}=0 & \text { if } & \beta^{\prime} Z_{k}+u_{k} \leq 0 \\
R_{k}=1 \text { if } & \mu_{R} \geq \beta^{\prime} Z_{k}+u_{k}>0 \\
R_{k}=2 & \text { if } & \beta^{\prime} Z_{k}+u_{k}>\mu_{R}
\end{array}
$$

where $R_{k}$ represents the discrete required qualification level that is necessary to properly perform the job, which must meet or exceed the latent, profit-maximizing education level, $R_{k}^{*}$.

\section{The Q-R Matching Process}

The error term in the individual's qualification equation, $e_{i}$, reflects heterogeneity in the skill of a worker of a given qualification level. Similarly, the error term in the firm's requirement equation, $u_{k}$, reflects heterogeneity in the necessary job skills for firms with a given requirement level. Although the correlation between the error terms is not perfect, our expectation (which is confirmed by subsequent empirical analysis) is that the error terms are positively correlated: a worker with unusually high skills (i.e., a high value for $e_{i}$ ) is likely to match with a firm with unusually high requirements (i.e., a high value for $u_{k}$ ). Our estimation procedure takes account of the correlation between the errors by estimating the two sets of equations (2 and 4) simultaneously.

Our model provides an explanation for this correlation. For example, our previous illustrations suggest that workers may initially match in jobs with lower requirements that provide training and/or a signal that permits them to move up the job-skill hierarchy in a subsequent period. Thus, a worker with a low value for $e_{i}$ is likely to match with a firm with a low value for $u_{k}$. This correlation thus provides some information regarding the match type. The observed qualification of the worker is $Q$ and the predicted qualification from the jointly estimated ordered probit model is $Q^{*}$. $Q^{*}$ reflects the correlation of worker qualifications with the matching firm's requirements. If a firm provides career mobility through training and signalling, then its low value for $u_{k}$ will lead to a predicted worker qualification level that 
is lower than the actual value: $\mathrm{Q}^{*}<\mathrm{Q}$. Similarly, if a worker has an unusually high skill level, then his high value for $e_{i}$ leads to a predicted firm requirement level that is higher than the actual value: $\mathrm{R}^{*}>\mathrm{R}$. The match types can be identified by the differences between $Q$ and $Q^{*}$ and $R$ and $R^{*}$, because these differences vary systematically across the match types.

First, consider an overeducated match such as a university-educated detective who initially places in a patrol officer job that requires a secondary school qualification but provides training for detective work. If the match is considered from the perspective of the worker's optimization problem, the observed qualification of a university degree is likely to be greater than would be predicted for a typical worker in a patrol officer's job. In other words, controlling for the type of job, workers who find it utility-maximizing to be in an overeducated-type match are more likely to place in a job such that the observed qualification exceeds the predicted qualification, $Q>Q^{*}$. However, from the perspective of the firm's optimization problem, the observed requirement of a secondary school qualification for a patrol officer's job is likely to be less than would be predicted for a typical worker who has a university degree. Specifically, controlling for the type of worker, firms that find it profitable to be in an overeducated-type match are more likely to hire a worker such that the observed requirement exceeds the predicted requirement, $R<R^{*}$.

Second, consider an undereducated match such as a patrol officer with a secondary school education who has been promoted into a detective job that typically requires a university degree. From the perspective of the worker's optimization problem, the observed secondary school qualification is likely to be less than would be predicted for a typical detective. In other words, controlling for the type of job, workers who find it utilitymaximizing to be in an undereducated type match are more likely to place in a job such that the observed qualifications are less than the predicted qualifications, $Q<Q^{*}$. From the perspective of the firm's optimization problem, the observed requirement of a university degree is likely to exceed the predicted requirement for a typical detective. Specifically, controlling for the type of worker, firms that find it profitable to be in an undereducated type match are more likely to hire a worker such that the observed requirements exceed the predicted requirements, $R>R^{*}$.

The overeducated- and undereducated type matches can be compared to one in which there is relatively little movement up the job hierarchy such that the worker and firm expect to have the qualifications equal the requirements throughout the life of the match. Specifically, controlling for the type of job, the observed qualification of a particular worker equals the predicted qualification of other workers in similar jobs such that, $Q=Q^{*}$. Likewise, 
controlling for the type of worker, the observed requirement for a particular job equals the predicted requirements of other workers who are similarly educated, $R=R^{*}$. The exactlyeducated match forms the base case where $Q=Q^{*}$ and $R=R^{*}$, which compares to an overeducated-type of match where $Q>Q^{*}$ and $R<R^{*}$ and an undereducated-type of match where $Q<Q^{*}$ and $R>R^{*}$.

The ordered probit models for $Q$ and $R$ specified above can be estimated simultaneously to control for the correlation in the observed matching process. The coefficients from the jointly estimated ordered probit models along with the observed attributes of the firm and the worker are used to predicted $Q^{*}$ and $R^{*}$ that condition on the observed match. The predicted and observed values of $Q$ and $R$ are then used to identify the match type.

How effectively the model identifies the type of match is tested empirically by examining whether the predicted match types yield the expected differences in training, promotion and wages. Specifically, our illustration suggests that workers in overeducated or undereducated-type matches are more likely to receive training early in their career and move up the job hierarchy than their exactly-educated counterparts who are comparably-placed and educated. Because the opportunities for training and promotion depend on where the person is in their career path, the empirical analysis makes use retrospective data that looks back at training and promotion opportunities in the pastand uses forward-looking data that ask workers about their expectations for training and promotion in the future in order to construct a picture of how these opportunities change over a career. In addition, wage regressions are estimated to test the hypothesis that both overeducated- and undereducated-type workers initially place into lower paying positions than they might otherwise achieve to subsequently achieve stronger wage growth through promotion or higher rates of return to tenure. Each of these empirical specifications include controls for whether the worker is in an overeducatedor undereducated-type match versus an exactly-educated-type match that are derived by comparing $Q$ versus $Q^{*}$ and $R$ versus $R^{*}$ along the lines predicted by the empirical model.

\section{The Data and Empirical Specification}

\section{A. The Data Source}

The data source for the empirical analysis is the Social Change and Economic Life Initiative (SCELI) dataset that surveyed 6,110 people in roughly equal numbers from six different labour markets - Aberdeen, Coventry, Kirkcaldy, Northampton, Rochdale and Swindon. The data were collected in June and July of 1986, using stratified random sampling to obtain a respondent sample representative of British working-age adults. The sample 
includes wage and salary workers and people who are self-employed, unemployed, or out of the labour force.

Our data set offers several advantages over other data sources. Our model implies that we must observe workers from the initial time of hire through subsequent promotions to detect the effects of overeducation and undereducation. Although a lengthy, comprehensive panel would be ideal for testing the model, existing panel datasets are inadequate. American datasets such as the PSID and CPS are short when compared to the time needed to observe the effects implied by our model. Although British datasets offer the advantage that the British educational qualification system yields a reasonably clear classification of overeducation and undereducation, they typically include few worker characteristics. Our detailed British cross-sectional dataset provides information on many workers who are at different stages in their careers. The data are unique in their detail of the individual, job, and firm attributes which are necessary to conduct the empirical analysis and their inclusion of backward-looking and forward-looking questions regarding training and promotion opportunities. Thus, the data allow us to classify workers as being undereducated or overeducated, and the variety of workers and firms allows us to infer the effects of the matching process on wages, promotions, and worker mobility.

The analysis uses a subset of these data that includes 1556 observations for male wage and salary workers who report all relevant information. Women are excluded to make our analysis comparable to prior work on overeducation (e.g., Cohn and Khan, 1995; Sicherman, 1991; Verdugo and Verdugo, 1989). The self-employed are excluded because the SCELI dataset includes only limited information regarding firm and job attributes for these workers. Individuals who are unemployed or out of the labour force are excluded for the obvious reason that an individual must be employed in order for us to observe differences between $Q$ and $R$.

\section{B. The Ordere d Probit Specification}

The data are first used to estimate the ordered-probit models. Observed qualifications and requirements, $Q$ and $R$, are delineated as low, medium and high with a numerical ordering of 0 through 2. High indicates an advanced degree (i.e., a degree or diploma from a university or college), medium indicates either an A-level, an apprenticeship, or an equivalent qualification, whereas low indicates none of these qualifications or requirements ${ }^{3}$. These

\footnotetext{
${ }^{3}$ A high qualification includes a Higher National Certificate (Diploma), a University Diploma, a Nursing and Teaching Qualification, and other professional, university or CNAA degree. A medium qualification includes a General or Scottish Certificate of Education (i.e., an A-level or Higher), a Certificate of Sixth Year Studies, City
} 
categories are sufficiently narrow to ensure differences among the $Q-R$ levels (i.e., $2>1>0$ ), but are sufficiently broad to ensure that each category has a similar $Q$ or $R$ (e.g., nurses and teachers have a similar level of education).

Following the empirical model, the ordered-probit specification for $Q$ includes family attributes that measure access to financial and human capital, and attitudinal/first-job attributes that measure labour-market commitment and opportunities, and the ordered-probit specification for $R$ includes measures of firm, job and labour market attributes. For brevity, the means of the explanatory variables used to estimate the ordered-probit models for $Q$ and $R$ are included in Appendix Tables 1 and 2 respectively, as well as for low, medium and high levels of $Q$ and $R$ and for the observed match types $Q>R, Q=R$, and $Q<R$. Consistent with expectations, the descriptive statistics do indicate that overeducated workers tend to be younger and undereducated workers older than their exactly-educated counterparts.

Maximum-likelihood estimates of the joint ordered-probit models for $Q$ and $R$ are presented in Table 1. The estimated correlation coefficient between the errors for $Q$ and $R$ is 0.573 and is significantly different from zero, which supports the contention that $Q$ and $R$ should be estimated simultaneously. However, the correlation coefficient is also significantly less than one, which indicates that actual and required qualifications are correlated but the match is far from exact.

The coefficients on the explanatory variables are generally significant and suggest that family background and labour-market opportunities affect the choice of actual qualifications whereas firm and job attributes affect required qualifications. Thus, those with more successful parents and those who delayed taking on family commitments are more likely to have acquired more education, whilst higher level jobs, jobs requiring a longer time to master, and jobs in firms which have seen recent reorganisation are likely to require more education. The joint ordered-probit specification is used to predict $Q^{*}$ and $R^{*}$ conditioned on the observed match.

The empirical tests of the model hinge on correctly predicting the match type of each worker. Thus, Table 2 presents a comparison between $Q^{*}$ and $R^{*}$ (which are respectively defined as the qualification or requirement category that has the maximum joint probability from the ordered-probit models) and the observed values of $Q$ and $R$ for workers who are observed to be overeducated $(Q>R)$, exactly-educated $(Q=R)$, and undereducated $(Q<R)$. The bold cells in Table 2 indicate that 89 percent of the 303 workers who are observed to be 
overeducated are predicted to have an overeducated-type of match (i.e., $Q>Q^{*}$ or $R<R^{*}$ ). Similarly, 89 percent of the 207 workers who are observed to be undereducated are predicted to have an undereducated type of match (i.e., $Q<Q^{*}$ or $R>R^{*}$ ). Moreover, whereas the majority of exactly-educated workers place in the centre cell where $Q^{*}=R^{*}$, the 46 percent of workers that are predicted to be in the surrounding cells may not be expected to be in an exactly-educated match throughout their career. Thus, the results in Table 2 broadly support the predictions of the theoretical model regarding the relationship between the predicted education level and the actual qualifications and requirements.

\section{The Match-Type Variables}

The empirical model appears to accurately predict the match type of workers who are observed to be overeducated or undereducated. However, whether the empirical model is truly effective at identifying the type of match depends on whether it can separate workers who are exactly educated throughout their career from those who are presently observed to have $Q=R$ but who are in an overeducated- or undereducated-type of match. Specifically, our illustrations suggest that workers who are in an overeducated- or an undereducated-type of match have greater training and promotion opportunities and steeper wage profiles relative to those who are exactly-educated throughout their career. To examine the ability of the empirical model to predict the type of match, we utilise the longitudinal aspects of the SCELI dataset to model the training and promotion opportunities of the different match types predicted by the empirical model, as well as the consequent effect upon earnings.

The match type is identified by four dummy variables derived from the predictions of the bivariate ordered probit model. These four mutually exclusive career development states are:

1. "OEOE" workers who are predicted to be in an overeducated-type of match (i.e., $Q>Q^{*}$ or $R<R^{*}$ ) and are observed to be overeducated presumably because they have yet to rise up the job hierarchy.

2. "MATCHOE" workers who are predicted to be in an overeducated-type of match (i.e., $Q>Q^{*}$ or $R<R^{*}$ ) but are observed to be exactly educ ated presumably because they have risen up the job hierarchy and therefore appear matched on the basis of their current match.

3. "MATCHUE" workers who are predicted to be in an undereducated type of match (i.e., $Q<Q^{*}$ or $R>R^{*}$ ) but are observed to be exactly educated presumably because they have yet to rise up the job hierarchy and therefore appear matched on the basis of their current match. 
4. "UEUE" workers who are predicted to be in an undereducated-type of match (i.e., $Q<Q^{*}$ or $R>R^{*}$ ) and are observed to be undereducated presumably because they have risen up the job hierarchy.

The excluded group of workers are those who are predicted to be in an exactly-educated type of match ("MATCH" workers) throughout their career.

The existing educational mismatch literature has tended to implicitly 'merge' the distinct MATCHOE, MATCH and MATCHUE career development states into one 'matched' group, ignoring the different career development paths of the MATCHOE and MATCHUE respondents and the implications that follow from these differences. The next section uses the four binary match variables in training, promotion, and wage equations to empirically examine whether the career path of workers who are predicted to be in an overeducated-and undereducated-type match differs from those who are exactly educated. Although it is likely that the identification of the match type is not exact, the coefficients on the match variables in the promotion, training and wage models would be biased towards zero and not support the model's predictions to the extent they are imprecise measures of the match type. In addition to the match-type variables, the empirical models include standard control variables used in wage and employment models. Descriptive statistics for the explanatory variables used in the promotion, training and wage regressions for all workers and disaggregated by match type are found in Appendix Table 3.

\section{Human Capital, Promotion, and Wage Results}

\section{A. Training and Experience}

Table 3 includes the results from two probit models that examine whether the roles of on-the-job experience and training differ by match type as expected. Specifically, the dependent variable in column 1 is a forward-looking, binary variable that equals one if the worker indicates that experience and training with the current firm is critical for future success on the job, whereas the dependent variable in column 2 is a backward looking, binary variable that equals one if the worker indicates that previously acquired experience and training is important for current success on the job. The predicted role of human capital depends on the stage of the worker's career; thus, by using forward- and backward-looking data, the analysis can examine the role of human capital over the career path. The results indicate that a number of the explanatory variables are significantly related to the dependent variable. Nonetheless, the discussion focuses on the binary match variables for brevity.

The coefficients on the binary variables measuring the match types are positive in the forward-looking human capital specification (column 1, Table 3) suggesting that experience 
within the firm is relatively important for overeducated- and undereducated-type matches. For overeducated type matches, only the coefficient on the OEOE dummy is significant suggesting that human capital (or the signal) acquired early on in the match when the worker is initially overeducated affects subsequent success on the job, whereas this firm-specific experience is less important when the worker has moved up the job hierarchy into an exactlyeducated match. On the other hand, both of the coefficients for the undereducated type of match (i.e., MATCHUE and UEUE) are significant with similar magnitudes. This result suggests that experience on the job is important throughout an undereducated-type match, which is consistent with the hypothesis that on-the-job training substitutes for formal education as workers move up the job hierarchy into a job for which they are undereducated.

The backward-looking results for the importance of past experience in the current job (column 2, Table 3) support those of the forward-looking measures. Specifically, the coefficients on the OEOE and MATCHUE dummies, measuring the two states that are expected to occur early in a career path and prior to the worker moving up the job hierarchy, are both negative and significant, which supports the contention that these match types discount pre-match training and experience. However, the coefficients on MATCHOE and UEUE, measuring the two states that are expected to occur later in a career and after the worker has moved up the job hierarchy, are both positive, which supports the contention that these matches relatively reward on-the-job experience. Interestingly, only the coefficient on UEUE is significantly positive indicating that experience is relatively important for undereducated-type workers (e.g., secondary-educated police officers), which is again consistent with the hypothesis that on-the-job experience may substitute for formal education. The insignificance of the MATCHOE coefficient could reflect the fact that formal education is relatively important once the overeducated worker is promoted into an exactly educated job (e.g., university-educated detective).

\section{B. Promotion}

Table 4 includes the results from a forward-looking and backward-looking discrete choice model of promotion. The explanatory variables are the same as those included in the prior human-capital models and a number are significant at traditional levels. Nonetheless, for the sake of brevity the discussion once again focuses on the binary variables measuring the match type.

The dependent variable in the first column is a forward-looking binary variable that equals one if the worker reports that he has a good chance of promotion in the next two years. The coefficients on three of the four match type variables are positive, but only the 
coefficient on OEOE is significant at traditional levels. The positive coefficient on OEOE is consistent with expectations, because overeducated-type workers are predicted to be overeducated early in their career prior their move up the job hierarchy. Undereducated-type workers who are observed to be exactly-educated are also predicted to eventually move up the job hierarchy; the lack of a significant, positive coefficient on MATCHUE may reflect the fact that promotion for undereducated type workers, whose promotion may require the acquisition of on-the-job experience to substitute for their lack of formal education (e.g., a secondary-educated police officer), may take longer than for an overeducated-type worker who already has the formal education. Likewise, the insignificance of coefficients on MATCHOE and UEUE may indicate the fact that these workers have already moved up the job hierarchy in response to their match.

The results presented in the second column of Table 4 are from an ordered discrete choice model. Specifically, the dependent variable is an ordered ranking of that compares the job segment of the current job with that of the first job. Specifically, the dependent variable takes on a value of $-1,0$, or 1 depending on whether the current job is, respectively, in a lower job segment, similar job segment, or higher job segment than the first job. Thus, the dependent variable is a backward-looking assessment of the discrete movements within the job hierarchy, which is estimated using an ordered-probit model.

The coefficients on the OEOE and MATCHUE dummies are negative and significant, which suggests that overeducated- and undereducated-type workers tend to be in lower socioeconomic job segments than comparable exactly educated workers early in their career. However, the coefficients on the MATCHOE and UEUE dummies are positive and significant, suggesting that overeducated- and undereducated-type workers tend to experience greater movements up the socio-economic job segments than comparable exactly educated workers. Thus, as expected, overeducated- and undereducated-type workers appear to experience greater career mobility.

The coefficients on the OEOE and MATCHUE dummies are negative and significant, which suggests that at this early stage in their careers they have yet to see those job changes that would bring the promotions to raise them from their current lower level jobs to the higher level jobs that we predict for them. Thus, OEOE type workers are still at lower job levels, and MATCHUE type workers are still at the same job levels, as comparable exactly educated workers. The likelihood that these future promotions will come has been established by column 1 of Table 3 and column 1 of Table 4. However, the positive and significant coefficients on the MATCHOE and UEUE dummies suggest that these overeducated-and 
undereducated-type workers have already seen the promotions up the job level hierarchy that we predict for them. Thus, MATCHOE type workers are now at the same job levels, and UEUE workers are now at higher job levels, than comparable exactly educated workers. Thus, as expected, overeducated-and undereducated-type workers appear to experience greater career mobility than their exactly-matched counterparts.

Jointly, the human capital and promotion results support the contention that workers in an overeducated- and undereducated-type match trade off a lower initial placement in the job hierarchy for on-the -job experience or training that yield a promotion return that arises from greater movement up the job hierarchy. This lower starting position and greater ascent up the job hierarchy for overeducated- and undereducated-type workers might be expected to yield a lower starting wage arising from either a wage discount to compensate the firm for the provision of on-the-job training or an initial discounting of pre-match human capital followed by greater wage growth reflecting either a promotion return or a higher-return to post match human capital. This hypothesis is examined next in several wage equations.

\section{Wage Profiles}

The empirical model predicts that overeducated- and undereducated-type workers will have steeper wage profiles. Specifically, overeducated- or undereducated-type workers may be viewed as initially placing into lower level jobs that yield a lower return to their pre-match human capital (i.e., education and pre-match experience) in exchange for a promotion return. Thus, Table 5 presents the results of two earnings equations using the log of weekly earnings that include pre-match human capital (distinct from tenure) and interactions of pre-match human capital with controls for match type. ${ }^{4}$ Once more, for the sake of brevity the focus of the discussion is on the match variables.

The first column of Table 5 presents the results from a log earnings model that includes controls for pre-match human capital (i.e., years of education and pre-match expe rience) and tenure, but excludes the match type variables. This specification is used as a point of comparison for column 2 that includes controls for the type of educational match. Specifically, column 2 includes two variables that measure the number of years of pre-match human capital multiplied by the binary variables that indicates whether they are in the early stage of the match (i.e., OEOE or MATCHUE workers). These interaction terms have

\footnotetext{
${ }^{4}$ Weekly earnings are used in the wage models following prior work that suggests that this measure has less measurement error than hourly earnings and controls for part-time work unlike annual earnings (e.g., Borjas, 1980). The number of observations is smaller in the wage equations than in the bivariate ordered probit model because some workers do not report their wage. However, the mean $Q$ and $R$ of workers who do and do not report their wage does not significantly differ and, thus, is not expected to bias the results in a particular direction.
} 
significantly negative coefficients and suggest a lower return to pre-match human capital for overeducated- and undereducated type workers early in their career. In addition, the model includes two binary variables that equal one if the worker is in an overeducated or undereducated type of match. These match type controls both have a positive and significant coefficient, suggesting that overeducated- and undereducated-type workers earn a promotion return later in their career. Interestingly, the initial discount to pre-match human capital plus the promotion return is not significantly different from zero at the sample means for overeducated or undereducated-type workers suggesting no market advantage from the type of match.

Alternatively, overeducated or undereducated-type workers may be viewed as trading off low initial pay for a higher return to post-match experience (i.e., tenure). Thus, Table 6 includes a control for post-match tenure (distinct from years of education and pre-match experience) and interactions of tenure with controls for match type. The base specification included in column 1 of Table 6 includes years of education, pre-match experience, and postmatch tenure without the controls for match type and yields results similar to previous wage specifications using British data sources. ${ }^{5}$

The specification in column 2 of Table 6 includes four controls for match type. Specifically, two binary variables are included for workers whom are predicted to be early in overeducated or undereducated job match (i.e., OEOE and MATCHUE). These match variables both have a negative sign, supporting the expectation that these workers initially earn lower wages. In addition, the model includes the worker's post-match tenure interacted with whether the worker is in an overeducated- or undereducated-type match, which both have a positive sign indicating a higher return to tenure for workers in overeducated and undereducated types of matches. Nonetheless, only two of the four match variables are significant at traditional levels. Thus, the interactive specification is broadly consistent with the predictions of the empirical model, but yields results that are relatively weak in statistical terms. ${ }^{6}$

\footnotetext{
${ }^{5}$ The coefficients in the wage equations, although different from those found using U.S. data sources, are typical of those found using U.K. data sources with the exception of a relatively low return to education. Our return to education estimates are not directly comparable to most U.K. studies that calculate the return using qualification dummies and not years of education. However, Polacheck and Siebert (1993) use data on men and women drawn from the 1972 General Household Survey of the U.K. to estimate a wage specification including the number of years of education and find a rate of return equal to 6.2 percent. We replicate their specification using men and women in SCELI (not presented), which also yields a return to education of 6.2 percent. Thus, the results are unlikely to be due to some unique attributes of the SCELI data.

${ }^{6}$ It is interesting that the coefficient on the tenure variable, while significant in the base specification in column 1 , is insignificant in column 2 and enters significantly only through its interaction with MATCHUE. This may suggest that the observed return to tenure in prior studies may result from those workers who concentrated in
} 


\section{Concluding Remarks}

Prior evidence from North America, Europe, and Asia indicates that the educational qualifications of up to a third of the world's workforce either exceed or fall short of the employer-specified education requirements for the job. Our paper provides the first holistic empirical examination of the matching process that shows how workers and firms can benefit from both an overeducated- or undereducated-type match where worker qualifications do not always equal firm requirements. Importantly, the paper demonstrates that, although workers and firms may not always be appropriately matched, the degree of mismatch in the labour market is likely to be smaller than the 30 percent of workers who are overeducated or undereducated at any point in time in the labour market.

In addition, our hedonic matching model shows that any comparisons in prior work between overeducated or undereducated workers and exactly educated workers using a crosssection or short panel dataset are likely to be misleading. Specifically, the overeducated are predicted to begin in low -paying, entry-level jobs early in their career that train them for higher-paying future positions that require their educational background, whereas the undereducated start in low -paying, exactly-educated jobs that, in time, can provide the training and signal that the worker has the necessary skills for promotion. It follows that all workers are likely to be exactly educated during some portion of their career, and thus the type of educational match cannot be directly observed. Nonetheless, our empirical model demonstrates how the educational match type can be imputed using joint ordered probit estimates of the differences between predicted and observed qualifications of the worker and predicted and observed requirements of the firm.

The empirical analysis uses uniquely-detailed data for British working-age males contained in the Social Change and Economic Life Initiative survey (SCELI) to estimate the hedonic matching model that identifies three types of educational matches (i.e., overeducated, undereducated, and exactly educated) and makes use of its forward-looking and backwardlooking data to show that on- the-job training and promotion opportunities are better for workers who are identified in overeducated/undereducated versus exactly educated type of match. Moreover, several wage equations demonstrate that overeducated and undereducated type workers have steeper wage profiles that reflect a trade -off between a lower pre-match return to human capital with a higher post-match acquisition of human capital or subsequent promotion return. Thus, this study provides the first formal evidence that both overeducation 
and undereducation may occur in labour market equilibrium and that tests of this hypothesis should be conducted over the life of the match. 


\section{References}

Alba-Ramirez, Alfonso "Mismatch in the Spanish Labour Market: Overeducation?" The Journal of Human Resources, Spring 1993 27(2):259-278.

Bauer, Thomas K. "Educational Mismatch and Wages: A Panel Analysis," The Economics of Education Review, June 2002, 21(3), 221-229.

Borghans, Lex and Andries de Grip The Overeducated Worker? The Economics of Skill Williston, Vt: International Distribution Corporation., 2000.

Borjas, George J. "The Relationship between Wages and Weekly Hours of Work: The Role of Division Bias," Journal of Human Resources, Summer. 1980, 15(3), 409- 23.

Chatterji, Monojit, Paul A. Seaman, and Larry D. Singell, Jr. "A Test of the Signalling Hypothesis," forthcoming Oxford Economic Papers.

Cohn, Elchanan and Shahina; Khan "The Wage Effects of Overschooling Revisited," Labour Economics, March 1995, 2(1), 67-76.

Duncan, Greg J. and Saul D. Hoffman, "The Incidence and Wage Effects of Overeducation." Economics of Education Review, Winter 1981 1(1), 57-86.

Groot, Wim and Hessel Oosterbeck "Earnings Effects of Different Components of Schooling Human Capital Versus Screening," Review of Economics and Statistics, May 1994 76(2), 317-21.

------- and Henriette Maassen van den Brink "Overeducation in the Labor Market: A MetaAnalysis," Economics of Education Review, April 2000a, 19(2), 149-58.

------ "Skill Mismatches in the Dutch Labor Market" International Journal of Manpower, 2000b, 21(7), 58495.

Hersch, Joni “Education Match and Job Match," Review of Economics and Statistics, February 1991, 73(1), 140-44.

Medes de Oliveira, M., M.C. Santos, and B.F. Kiker, "The Role of Human Capital and Technological Change in Overeducation," Economics of Education Review, April 2000, 19(2), 199-206.

$\mathrm{Ng}$, Ying Chu "Overeducation and Undereducation and Their Effect on Earnings: Evidence from Hong Kong, 1986-1996," Pacific Economic Review, October 2001, 6(3), 401418.

Robst, John "College Quality and Overeducation," Economics of Education Review, September 1995, 14(3), 221-228. 
Rumberger, Russell W., Overeducation in the U.S. Labour Market. New York, NY: Praeger., 1981.

-------. "The Impact of Surplus Schooling on Productivity and Earnings," Journal of Human Resources, Winter 1987, 22(1), 25-50.

Sicherman, Nachum and Oded Galor "A Theory of Career Mobility," Journal of Political Economy, February 1990, 98(1), 169-92.

Sicherman, Nachum and Oded Galor "Overeducation in the Labour Market," Journal of Labour Economics, April 1991, 9(2), 101-122.

Sloane, Peter, Harminder Battu, and Paul Seaman "Overeducation and the Formal Education / Experience and Training Trade-off", with P. Sloane and H. Battu, Applied Economic Letters, 1996, No.3, 511-515.

------- "Overeducation, Undereducation, and the British Labour Market," Applied Economics, 1999, Vol. 31, 1437-1453.

Jaeger, David A. and Marianne E. Page, "Degrees Matter: New Evidence on Sheepskin Effects in the Returns to Education," Review of Economics and Statistics, November 1996, 78(4), 733-740.

Manacorda, Marco and Barbara Petrongolo "Skill Mismatch and Unemployment in OECD Countries," Wirtschaftpolitische Blatter, 2000, 47(1), 72-82.

Vahey, Shaun P. "The Great Canadian Training Robbery: Evidence on the Returns to Educational Mismatch” Economics of Education Review, April 2000, 19(2), 219-27.

Verdugo, Richard. R. and Naomi. T. Verdugo "The Impact of Surplus Schooling on Earnings”, Journal of Human Resources, Fall 1989, Vol. 24(4), 629-43. 
Table 1 : Bivariate Ordinal Probit Results ${ }^{\mathrm{a}}$

Qualifications $(Q)$

Requirements $(R)$

\begin{tabular}{|c|c|c|c|c|c|}
\hline Variable & Coefficient & $\begin{array}{c}\text { Asymptotic } \\
t \text {-value }\end{array}$ & Variable & Coefficient & $\begin{array}{c}\text { Asymptotic } \\
t \text {-value }\end{array}$ \\
\hline Mother Out of Work & -0.202 & -3.466 & Professional & 1.244 & 10.806 \\
\hline Mother White Collar & 0.179 & 0.739 & Non Manual & 1.045 & 9.517 \\
\hline Mother Self Employed & -0.242 & -0.899 & Skilled Manual & 0.514 & 5.060 \\
\hline Father Out of Work & -0.163 & -1.797 & Employees $>500$ & 0.206 & 3.083 \\
\hline Father White Collar & 0.415 & 4.554 & Insider is Important & -0.056 & -0.769 \\
\hline Father Self Employed & 0.124 & 1.292 & Union & -0.099 & -1.601 \\
\hline Age & -0.006 & -2.222 & Requirements Nec. & 0.767 & 11.702 \\
\hline Married at Age 20 & -0.259 & -2.995 & Time to Proficiency & 0.150 & 6.151 \\
\hline Kids at Age 20 & -1.422 & -2.815 & Years of Training & 0.062 & 2.538 \\
\hline Work Natural & -0.298 & -2.797 & Good Promotion Prspt. & 0.078 & 1.204 \\
\hline Work if Rich & 0.084 & 1.470 & Sprvis. Effects Work & -0.073 & -1.119 \\
\hline Men are Prime Earner & 0.363 & 5.194 & Reorg. in Last 5 Yrs. & 0.148 & 2.470 \\
\hline Men's Jobs Come First & 0.220 & 3.305 & Part-Time Job & -0.223 & -0.793 \\
\hline Public Sector Job & 0.279 & 4.172 & Log of Hours Worked & -0.210 & -1.319 \\
\hline Hours Worked: $35-40$ & -0.223 & -1.962 & Unemployment Rate & 0.009 & 1.202 \\
\hline Hours Worked: $>40$ & -0.278 & -2.358 & - & - & - \\
\hline Supervisory Resp. & 0.495 & 3.481 & - & - & - \\
\hline Cowrks. Mainly Men & -0.036 & -0.593 & - & - & - \\
\hline Good Promotion Prspt. & 0.180 & 3.282 & - & - & - \\
\hline Central England & -0.168 & -2.128 & - & - & - \\
\hline Northern England & -0.009 & -0.104 & - & - & - \\
\hline Urban Scotland & 0.011 & 0.141 & - & - & - \\
\hline Rural Scotland & 0.672 & 2.019 & - & - & - \\
\hline Other Countries & 0.014 & 0.074 & - & - & - \\
\hline Constant & 0.537 & 3.128 & Constant & -0.705 & -1.144 \\
\hline$\mu_{2}$ & 1.010 & 26.361 & $\mu_{1}$ & 1.002 & 22.295 \\
\hline
\end{tabular}

Number of observations $=1556$

Log-likelihood $=-2614.97$

Estimated correlation $(\rho)=0.573$, standard error $=0.030$

a - In the qualification equations, the explanatory variable 'age' is continuous while the rest are binary variables that equal one if the variable description is true. In the requirement equation, the explanatory variables time to proficiency, years of training, the log of hours worked, and the unemployment rate are continuous while the rest are binary variables that equal one if the variable description is true. The excluded region is Southern England. 
Table 2 : Predicted and Observed Qualifications and Requirements Comparisons: Percent in Each Category ${ }^{\mathrm{a}}$

\begin{tabular}{|c|c|c|c|c|}
\hline \multicolumn{5}{|c|}{ Overeducated: $Q>R($ Number of Observations $=303)$} \\
\hline & $R<R^{*}$ & $R=R^{*}$ & $R>R^{*}$ & Total \\
\hline$Q=Q^{*}$ & 10.23 & 10.23 & 0.00 & 20.46 \\
\hline$Q<Q^{*}$ & 5.61 & 0.33 & 0.00 & 5.94 \\
\hline$Q>Q^{*}$ & 3.30 & 63.04 & 7.26 & 73.60 \\
\hline Total & 19.14 & 73.60 & 7.26 & 100.00 \\
\hline \multicolumn{5}{|c|}{ Exactly Educated: $Q=R($ Number of Observations $=1046)$} \\
\hline & $R<R^{*}$ & $R=R^{*}$ & $R>R^{*}$ & Total \\
\hline$Q<Q^{*}$ & 6.69 & 7.84 & 0.00 & 14.53 \\
\hline$Q=Q^{*}$ & 2.39 & 53.73 & 2.10 & 58.22 \\
\hline$Q>Q^{*}$ & 0.00 & 6.21 & 21.03 & 27.24 \\
\hline Total & 9.08 & 67.78 & 23.13 & 100.00 \\
\hline \multicolumn{5}{|c|}{ Undereducated: $Q<R($ Number of Observations $=207)$} \\
\hline & $R<R^{*}$ & $R=R^{*}$ & $R>R^{*}$ & Total \\
\hline$Q<Q^{*}$ & 8.21 & 16.43 & 3.38 & 28.02 \\
\hline$Q=Q^{*}$ & 0.48 & 10.63 & 43.96 & 55.07 \\
\hline$Q>Q^{*}$ & 0.00 & 0.00 & 16.91 & 16.91 \\
\hline Total & 8.69 & 27.06 & 64.25 & 100.00 \\
\hline
\end{tabular}

a $-Q$ and $R$ are the observed qualifications and requirements that can take on a value of 2 (college degree) 1 (at least one A-level) and 0 (no A-level exams). $Q^{*}$ and $R^{*}$ are the predicted qualification and requirement levels from the joint ordered probit model. Overeducated types of matches are predicted to have $R<R^{*}$ and $Q>Q^{*}$, whereas undereducated types of matches are predicted to have $R>R^{*}$ and $Q<Q^{*}$. 
Table 3 : Forward- and Backward-looking Human Capital Specifications ${ }^{\mathrm{a}}$

Being an insider is useful for obtaining promotion in your current firm

\begin{tabular}{lcccc} 
& \multicolumn{2}{c}{ current firm } & \multicolumn{2}{c}{ success in the current job } \\
\hline Variable & Coefficient & $\begin{array}{c}\text { Asymp. } \\
t \text {-value }\end{array}$ & Coefficient & $\begin{array}{c}\text { Asymp. } \\
t \text {-value }\end{array}$ \\
\hline OEOE & 0.219 & 2.48 & -0.245 & -2.75 \\
MATCHOE & 0.137 & 0.97 & 0.197 & 1.26 \\
MATCHUE & 0.262 & 1.94 & -0.296 & -2.18 \\
UEUE & 0.251 & 2.41 & 0.509 & 4.24 \\
Years of Education & 0.011 & 0.63 & 0.053 & 2.94 \\
Years of Experience & -0.0001 & -0.03 & 0.004 & 0.92 \\
Employees>500 & 0.181 & 2.44 & -0.027 & -0.35 \\
Trade Union Member & 0.089 & 1.30 & -0.243 & -3.44 \\
Unemployment Rate & -0.002 & -0.28 & -0.007 & -0.74 \\
Married & -0.114 & -1.27 & 0.093 & 1.01 \\
Number of Dependent Children & 0.067 & 1.88 & 0.047 & 1.23 \\
First Job was Professional & 0.310 & 2.11 & 0.240 & 1.50 \\
First Job was Lower Non-manual & 0.203 & 2.17 & 0.168 & 1.74 \\
First Job Was Skilled Manual & 0.112 & 1.40 & 0.240 & 2.95 \\
Constant & -0.614 & -2.44 & -0.226 & -0.86 \\
\hline Number of observations & \multicolumn{3}{c}{1551} \\
Log likelihood & -1027.40 & & -939.35 & \\
\hline
\end{tabular}

a - The variable OEOE (MATCHOE) is a binary variable that equals one if a worker who is predicted to be in an overeducated (OE) type mach is observed to have qualifications that exceed (equal) requirements. The variable UEUE (MATCHUE) is a binary variable that equals one if a worker who is predicted to be in an undereducated (UE) type match is observed to have qualifications that fall short of (equal) requirements. The variables years of education, years of experience, unemployment rate, and number of dependent children are continuous, whereas the remaining variables are binary and equal one if the description is true. 
Table 4 : Forward- and Backward-looking Promotion Specifications ${ }^{\mathrm{a}}$

\begin{tabular}{|c|c|c|c|c|}
\hline \multirow[b]{2}{*}{ Variable } & \multicolumn{2}{|c|}{$\begin{array}{l}\text { Very or quite good chance of a } \\
\text { better job in the next two years }\end{array}$} & \multicolumn{2}{|c|}{$\begin{array}{c}\text { Job level changes over the } \\
\text { career to date }\end{array}$} \\
\hline & Coefficient & $\begin{array}{l}\text { Asymp. } \\
t \text {-value }\end{array}$ & Coefficient & $\begin{array}{l}\text { Asymp. } \\
t \text {-value }\end{array}$ \\
\hline OEOE & 0.306 & 3.36 & -0.205 & -2.31 \\
\hline MATCHOE & 0.200 & 1.38 & 1.100 & 5.75 \\
\hline MATCHUE & -0.038 & -0.28 & 0.871 & -6.07 \\
\hline UEUE & 0.114 & 1.07 & 0.694 & 3.76 \\
\hline Years of Education & 0.061 & 3.54 & 0.110 & 6.59 \\
\hline Years of Experience & -0.023 & -5.77 & 0.016 & 4.47 \\
\hline Employees $>500$ & 0.091 & 1.19 & -0.050 & -0.71 \\
\hline Trade Union Member & -0.391 & -5.64 & -0.199 & -3.08 \\
\hline Unemployment Rate & -0.015 & -1.72 & -0.006 & -0.79 \\
\hline Married & -0.096 & -1.05 & 0.035 & 0.41 \\
\hline Number of Dependent Children & 0.044 & 1.20 & 0.111 & 3.19 \\
\hline First Job was Professional & 0.059 & 0.39 & -2.139 & -14.36 \\
\hline First Job was Lower Non-manual & 0.130 & 1.37 & -1.139 & -12.14 \\
\hline First Job Was Skilled Manual & -0.016 & -0.19 & -0.989 & -12.53 \\
\hline Constant & -0.231 & -0.90 & & \\
\hline Threshold 1 & & & -0.558 & 2.30 \\
\hline Threshold 2 & & & 0.643 & 2.65 \\
\hline Number of observations & \multicolumn{2}{|c|}{1551} & \multicolumn{2}{|c|}{$1506^{b}$} \\
\hline Log likelihood & \multicolumn{2}{|c|}{-972.428} & \multicolumn{2}{|c|}{-1330.9192} \\
\hline
\end{tabular}

a - The variable OEOE (MATCHOE) is a binary variable that equals one if a worker who is predicted to be in an overeducated $(\mathrm{OE})$ type match is observed to have qualifications that exceed (equal) requirements. The variable UEUE (MATCHUE) is a binary variable that equals one if a worker who is predicted to be in an undereducated (UE) type match is observed to have qualifications that fall short of (equal) requirements. The variables years of education, years of experience, unemployment rate, and number of dependent children are continuous, whereas the remaining variables are binary and equal one if the description is true.

$\mathrm{b}$ - There are fewer observations for job level changes because some workers have not changed jobs. The other human capital and promotion results are not qualitatively affected if the observations are restricted to the 1506 for observed job changers. 
Table 5 : Wage Regressions Using Pre-Match Human Capital Interactions ${ }^{\text {a }}$

\begin{tabular}{lcccc}
\hline Variable & Coeff. & $t$-value & Coeff. & $t$-value \\
\hline Overeducated Match Type & - & - & 0.087 & 1.91 \\
(Pre-Match Human Capital)*(OEOE) & - & - & -0.005 & -2.48 \\
Undereducated Match Type & - & - & 0.104 & 2.85 \\
(Pre-Match Human Capital)*(MATCHUE) & - & - & -0.005 & -2.11 \\
Pre-Match Human Capital & 0.098 & 7.10 & 0.010 & 7.43 \\
Tenure & 0.046 & 2.17 & 0.039 & 1.82 \\
Employees>500 & 0.176 & 6.60 & 0.167 & 6.24 \\
Trade Union Member & -0.007 & -0.26 & 0.006 & 0.24 \\
Unemployment Rate & -0.014 & -4.62 & -0.014 & -4.73 \\
Married & 0.098 & 2.92 & 0.096 & 2.87 \\
Number of Dependent Children & 0.075 & 5.75 & 0.075 & 5.72 \\
First Job was Professional & 0.196 & 3.64 & 0.191 & 3.55 \\
First Job was Lower Non-manual & 0.114 & 3.39 & 0.104 & 3.10 \\
First Job Was Skilled Manual & 0.074 & 2.60 & 0.073 & 2.56 \\
Constant & 4.493 & 48.55 & 4.472 & 47.84 \\
\hline Number of observations & \multicolumn{2}{c}{$1379^{b}$} \\
Adjusted R ${ }^{2}$ & \multicolumn{2}{c}{1379} \\
\hline
\end{tabular}

a - Pre-match human capital is a measure of years of education and experience acquired prior to the job match. The variable Overeducated Match Type (Undereducated Match Type) is a binary variables that equals 1 for OEOE or MATCHOE (UEUE or MATCHUE) workers.

$\mathrm{b}$ - There are fewer observations in the wage regressions than the promotion and human capital models because some workers do not r eport earnings. The qualitative conclusions of the previous promotion and human capital specifications do not change if the sample is restricted to those workers for whom there are earnings data. 
Table 6 : Wage Regressions with Tenure Interactions ${ }^{\mathrm{a}}$

\begin{tabular}{lcccc}
\hline Variable & Coeff. & $t$-value & Coeff. & $t$-value \\
\hline OEOE & - & - & -0.064 & -1.73 \\
(Tenure)*(Overeducated Match Type) & - & - & 0.005 & 1.19 \\
MATCHUE & - & - & -0.076 & -1.51 \\
(Tenure)*(Undereducated Match Type) & - & - & 0.008 & 2.22 \\
Years of Education & 0.411 & 6.59 & 0.041 & 6.49 \\
Years of Pre-Match Experience & 0.010 & 7.10 & 0.010 & 6.78 \\
Tenure & 0.005 & 2.17 & 0.001 & 0.49 \\
Employees>500 & 0.176 & 6.60 & 0.172 & 6.44 \\
Trade Union Member & -0.007 & -0.26 & 0.001 & 0.03 \\
Unemployment Rate & -0.014 & -4.62 & -0.014 & -4.65 \\
Married & 0.098 & 2.92 & 0.095 & 2.83 \\
Number of Dependent Children & 0.075 & 5.75 & 0.074 & 5.63 \\
First Job was Professional & 0.196 & 3.64 & 0.192 & 3.56 \\
First Job was Lower Non-manual & 0.114 & 3.39 & 0.112 & 3.35 \\
First Job Was Skilled Manual & 0.074 & 2.60 & 0.074 & 2.59 \\
Constant & 4.493 & 48.55 & 4.53 & 48.06 \\
\hline Number of observations & \multicolumn{2}{c}{$1379^{b}$} \\
Adjusted R ${ }^{2}$ & 0.1951 & \multicolumn{2}{c}{0.1379} \\
\hline a The & \multicolumn{2}{c}{0.1975} \\
\hline
\end{tabular}

a - The variable Overeducated Match Type (Undereducated Match Type) is binary variables that equals 1 for OEOE or MATCHOE (UEUE or MATCHUE) workers.

$\mathrm{b}$-There are fewer observations in the wage regressions than the promotion and human capital model because some workers do not report earnings. The qualitative conclusions of the previous promotion and human capital specifications do not change if the sample is restricted to those workers for whom there are earnings data. 
Appendix Table 1 : Variable Means for Qualifications ${ }^{\mathrm{a}}$

$$
\text { Variable }
$$

Family Background

Mother Out of Work

Mother White Collar

Mother Self Employed

Father Out of Work

Father White Collar

Father Self Employed

Work Attitudes

Age

Married at Age 20

Kids at Age 20

Work Natural

Work if Rich

Men are Primary Earner

Men's Jobs Come First

Labour Market Attributes

Public Sector Job

Hours Worked: $35-40$

Hours Worked: $>40$

Supervisory Resp.

Coworkers Mainly Men

Good Promotion Prspt.

Central England

Northern England

Urban Scotland

Rural Scotland

Other Countries

description is true. The excluded region is Southern England

\begin{tabular}{|c|c|c|c|c|c|}
\hline $\begin{array}{c}Q=0 \\
(633 \text { obs. })\end{array}$ & $\begin{array}{c}Q=1 \\
\text { (530 obs.) }\end{array}$ & $\begin{array}{c}Q=2 \\
(393 \text { obs. })\end{array}$ & $\begin{array}{c}Q>R \\
(303 \text { obs. })\end{array}$ & $\begin{array}{c}Q=R \\
\text { (1046 obs.) }\end{array}$ & $\begin{array}{c}Q<R \\
\text { (207 obs.) }\end{array}$ \\
\hline 0.403 & 0.285 & 0.277 & 0.281 & 0.341 & 0.353 \\
\hline 0.008 & 0.013 & 0.018 & 0.017 & 0.011 & 0.010 \\
\hline 0.009 & 0.011 & 0.010 & 0.013 & 0.010 & 0.010 \\
\hline 0.134 & 0.094 & 0.069 & 0.092 & 0.111 & 0.087 \\
\hline 0.057 & 0.091 & 0.221 & 0.109 & 0.114 & 0.092 \\
\hline 0.077 & 0.079 & 0.117 & 0.083 & 0.093 & 0.072 \\
\hline 38.87 & 35.438 & 36.962 & 34.716 & 37.256 & 40.696 \\
\hline 0.148 & 0.125 & 0.051 & 0.096 & 0.118 & 0.135 \\
\hline 0.011 & 0.004 & 0 & 0 & 0.006 & 0.014 \\
\hline 0.093 & 0.066 & 0.038 & 0.069 & 0.069 & 0.077 \\
\hline 0.611 & 0.668 & 0.715 & 0.630 & 0.670 & 0.628 \\
\hline 0.158 & 0.213 & 0.310 & 0.261 & 0.206 & 0.198 \\
\hline 0.180 & 0.257 & 0.293 & 0.188 & 0.249 & 0.232 \\
\hline 0.156 & 0.200 & 0.356 & 0.205 & 0.234 & 0.184 \\
\hline 0.463 & 0.489 & 0.471 & 0.508 & 0.476 & 0.411 \\
\hline 0.491 & 0.457 & 0.407 & 0.432 & 0.447 & 0.551 \\
\hline 0.019 & 0.030 & 0.109 & 0.026 & 0.054 & 0.029 \\
\hline 0.717 & 0.747 & 0.618 & 0.696 & 0.703 & 0.710 \\
\hline 0.427 & 0.485 & 0.649 & 0.465 & 0.507 & 0.536 \\
\hline 0.294 & 0.283 & 0.226 & 0.238 & 0.273 & 0.324 \\
\hline 0.177 & 0.183 & 0.204 & 0.188 & 0.193 & 0.145 \\
\hline 0.291 & 0.370 & 0.252 & 0.337 & 0.303 & 0.290 \\
\hline 0.005 & 0.002 & 0.020 & 0.017 & 0.005 & 0.010 \\
\hline 0.025 & 0.017 & 0.033 & 0.023 & 0.024 & 0.029 \\
\hline
\end{tabular}

0.023

0.029 
Appendix Table 2 : Variable Means for Requirements ${ }^{\mathrm{a}}$

\begin{tabular}{|c|c|c|c|c|c|c|}
\hline Variable & $\begin{array}{c}R=0 \\
\text { (758 obs.) }\end{array}$ & $\begin{array}{c}R=1 \\
\text { (397 obs.) }\end{array}$ & $\begin{array}{c}R=2 \\
\text { (401 obs.) }\end{array}$ & $\begin{array}{c}Q>R \\
(303 \text { obs.) }\end{array}$ & $\begin{array}{c}Q=R \\
(1046 \text { obs. })\end{array}$ & $\begin{array}{c}Q<R \\
(207 \text { obs.) }\end{array}$ \\
\hline \multicolumn{7}{|l|}{ Firm Attributes } \\
\hline Professional & 0.111 & 0.161 & 0.501 & 0.175 & 0.225 & 0.295 \\
\hline Non Manual & 0.165 & 0.237 & 0.389 & 0.264 & 0.229 & 0.266 \\
\hline Skilled Manual & 0.358 & 0.504 & 0.100 & 0.307 & 0.328 & 0.362 \\
\hline Employees $>500$ & 0.261 & 0.264 & 0.327 & 0.244 & 0.270 & 0.377 \\
\hline Insider is Important & 0.773 & 0.776 & 0.810 & 0.799 & 0.774 & 0.807 \\
\hline Union & 0.544 & 0.531 & 0.476 & 0.508 & 0.537 & 0.473 \\
\hline \multicolumn{7}{|l|}{ Job Attributes } \\
\hline Requirements Necessary & 0.222 & 0.768 & 0.778 & 0.363 & 0.518 & 0.643 \\
\hline Time to Proficiency & 0.856 & 1.802 & 1.762 & 1.123 & 1.315 & 1.716 \\
\hline Years of Training & 0.349 & 0.896 & 1.026 & 0.652 & 0.608 & 0.957 \\
\hline Good Promotion Prspt. & 0.542 & 0.620 & 0.786 & 0.611 & 0.614 & 0.700 \\
\hline Supervision Effects Wrk. & 0.259 & 0.307 & 0.262 & 0.287 & 0.270 & 0.261 \\
\hline Job Reorg. in Last 5 Yrs. & 0.409 & 0.401 & 0.529 & 0.419 & 0.424 & 0.531 \\
\hline Part-Time Job & 0.021 & 0.013 & 0.017 & 0.020 & 0.018 & 0.014 \\
\hline $\begin{array}{l}\text { Log of Hours Worked } \\
\text { Labour Market Attributes }\end{array}$ & 3.670 & 3.662 & 3.642 & 3.671 & 3.655 & 3.673 \\
\hline Unemployment Rate & 13.267 & 13.523 & 12.753 & 12.905 & 13.266 & 13.295 \\
\hline
\end{tabular}

a - The explanatory variables time to proficiency, years of training, the log of hours worker, and the

unemployment rate are continuous, while the rest are binary variables that equal one if the variable description is true. 
Appendix Table 3 : Variable Means for Career Development States

\begin{tabular}{cccccc}
\hline Variable & $\begin{array}{c}\text { All cases } \\
(1550 \mathrm{obs})\end{array}$ & $\begin{array}{c}\text { OEOE } \\
(213 \mathrm{obs})\end{array}$ & $\begin{array}{c}\text { MATCHOE } \\
(65 \mathrm{obs})\end{array}$ & $\begin{array}{c}\text { MATCHUE } \\
(79 \mathrm{obs})\end{array}$ & $\begin{array}{c}\text { UEUE } \\
(51 \mathrm{obs})\end{array}$ \\
\hline Years of Education & 11.1987 & 10.8122 & 12.0000 & 10.6202 & 11.5098 \\
Total Experience & 14.9755 & 15.0440 & 17.1397 & 9.2705 & 16.7633 \\
Employees $>500$ & 0.2794 & 0.2207 & 0.4000 & 0.2658 & 0.4314 \\
Trade Union Member & 0.5239 & 0.5070 & 0.4000 & 0.5570 & 0.3725 \\
Unemployment Rate & 13.1845 & 12.9315 & 13.0454 & 14.0684 & 13.9794 \\
Married & 0.7052 & 0.6714 & 0.8154 & 0.4684 & 0.7647 \\
Number of Dependent Children & 0.7929 & 0.7746 & 1.0462 & 0.5696 & 0.9020 \\
First Job was Professional & 0.0703 & 0.0188 & 0.1231 & 0.0380 & 0.01569 \\
\hline
\end{tabular}

a - The variable OEOE (MATCHOE) is a binary variable that equals one if a worker who is predicted to be in an overeducated $(\mathrm{OE})$ type match is observed to have qualifications that exceed (equal) requirements. The variable UEUE (MATCHUE) is a binary variable that equals one if a worker who is predicted to be in an undereducated (UE) type match is observed to have qualifications that fall short of (equal) requirements. 